Supporting information

\title{
Monte-Carlo analysis-based CapEx uncertainty estimation of new technologies: the case of photochemical lamps
}

Levente L. Simon ${ }^{1 *}$, Michael Dieckmann ${ }^{1}$, Alan Robinson ${ }^{2}$, Thomas Vent-Schmidt ${ }^{1}$, Dominique Marantelli ${ }^{1}$, Ralf Kohlbrenner ${ }^{1}$, Alexandre Saint-Dizier ${ }^{1}$, Denis Gribkov ${ }^{1}$, Jean-Philippe Krieger ${ }^{1}$

${ }^{1}$ Syngenta Crop Protection AG, Process Technology New Active Ingredients, Breitenloh 5, 4333 Münchwilen, Switzerland

${ }^{2}$ Syngenta Crop Protection AG, Process Research Stein, Schaffhausener Str. 101, 4332

* Corresponding author: levente.simon@syngenta.com, Tel: +41628685672 


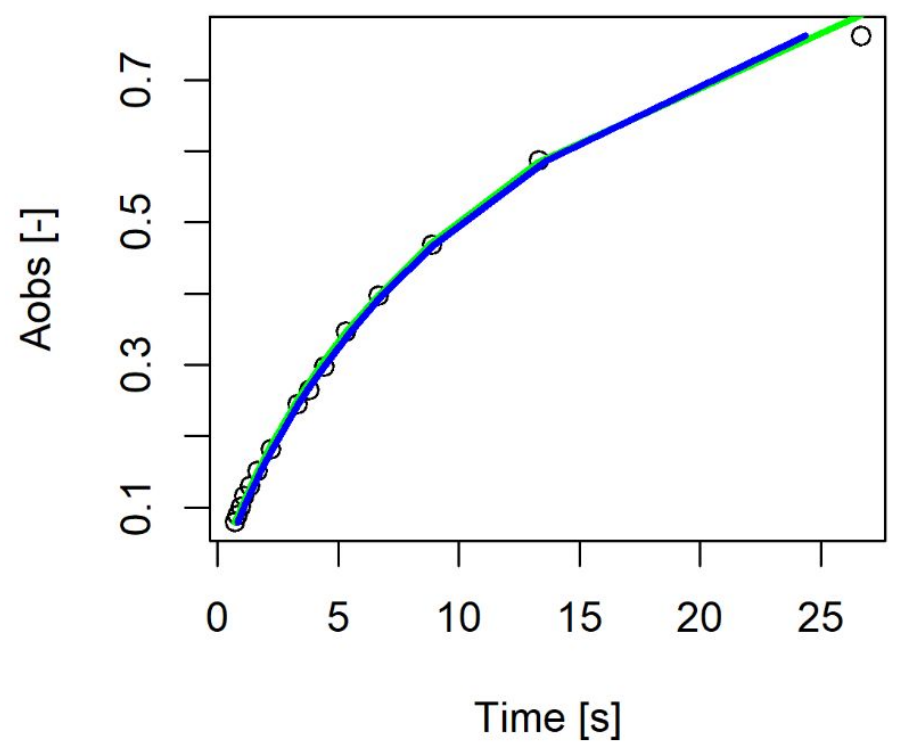

Figure S1 Comparison of analytical solution (blue) with the integrated equation (green) for the $5^{\text {th }}$ data set presented by Aillet et al. ${ }^{1}$ Circles are experimental data. 
Nonlinear optimization convergency results

Convergence results of the $p_{\text {tube }}$ fitting algorithm. Convergence is shown by the 0 value of the function output.

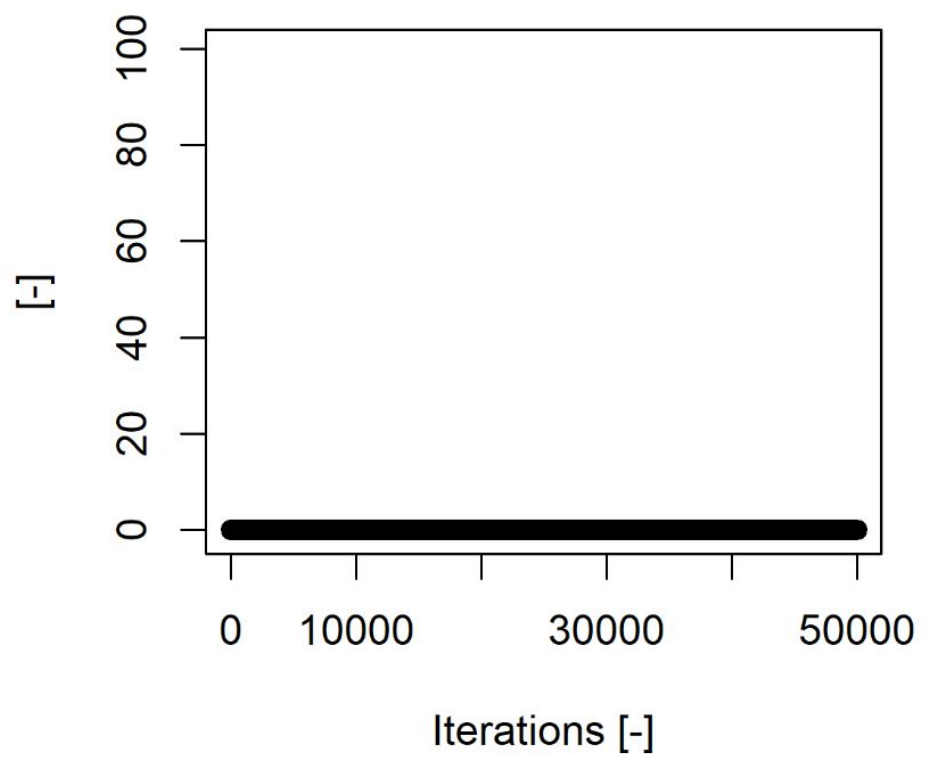

Figure S2 Nonlinear optimization convergence analysis of Scenario 1.

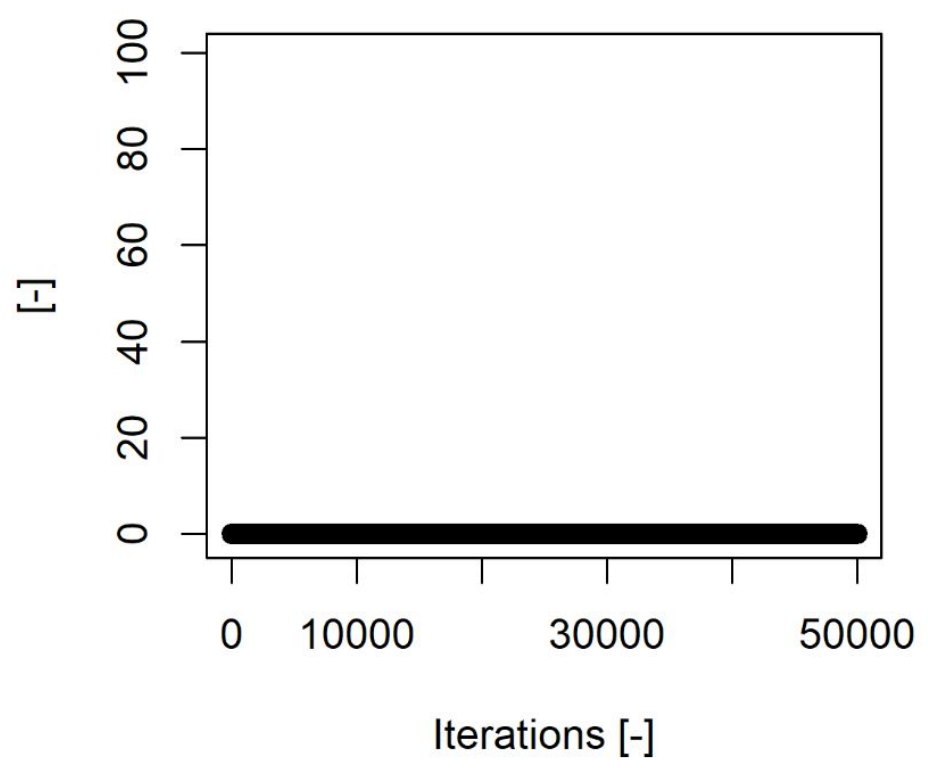

Figure S3 Nonlinear optimization convergence analysis of Scenario 2. 


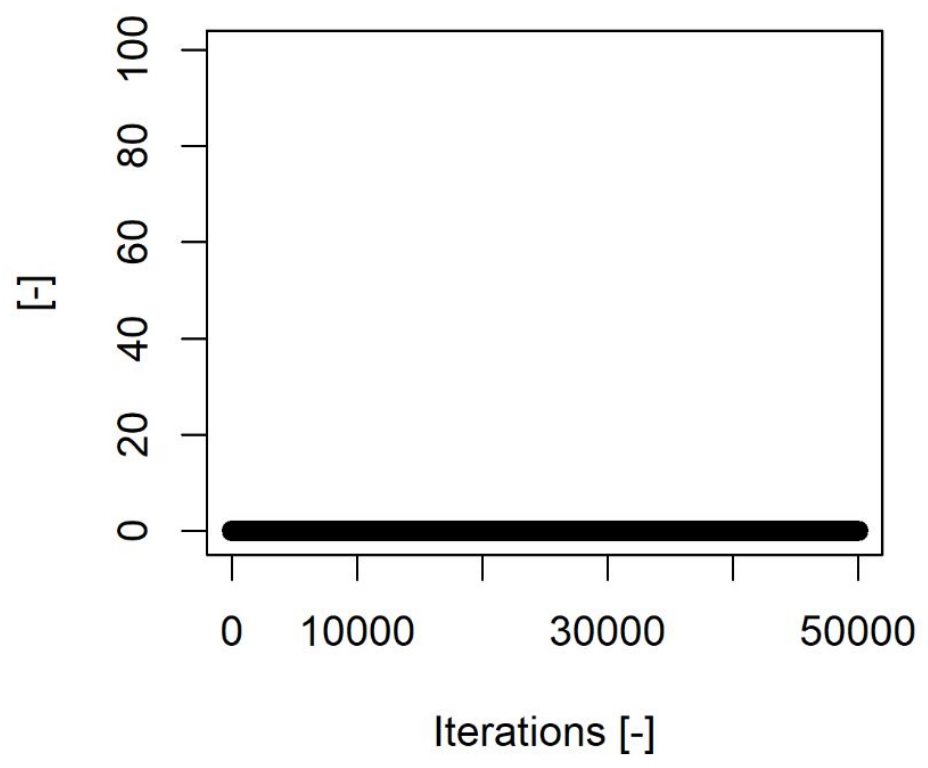

Figure S4 Nonlinear optimization convergence analysis of Scenario 3.

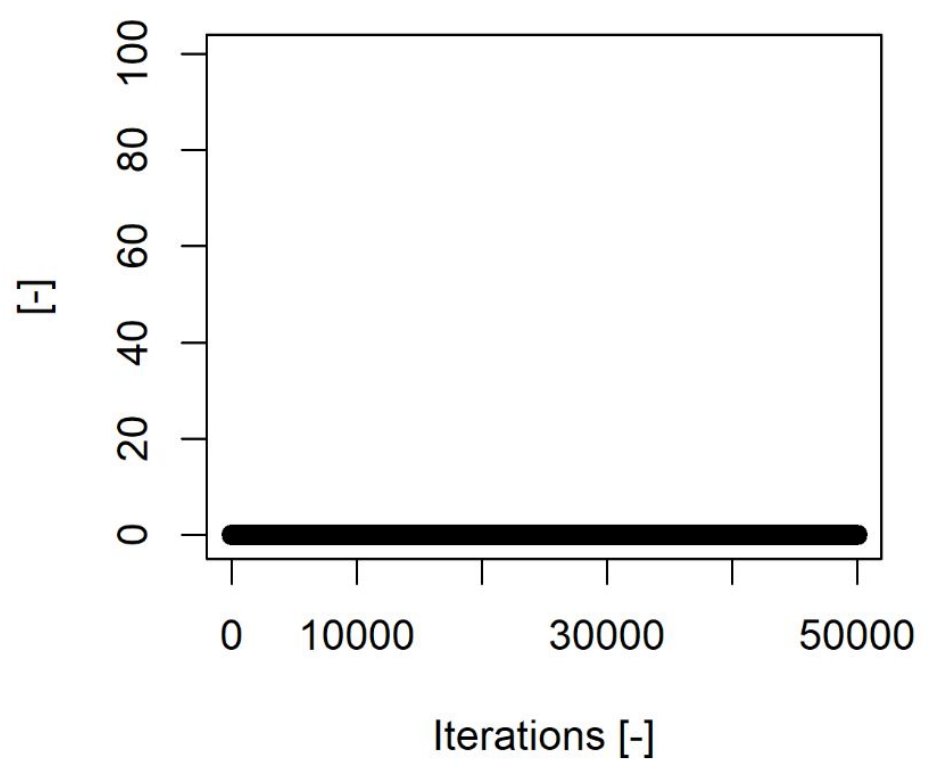

Figure S5 Nonlinear optimization convergence analysis of Scenario 4. 
Convergence of the standard deviation and mean of the scaled-up photon rates.
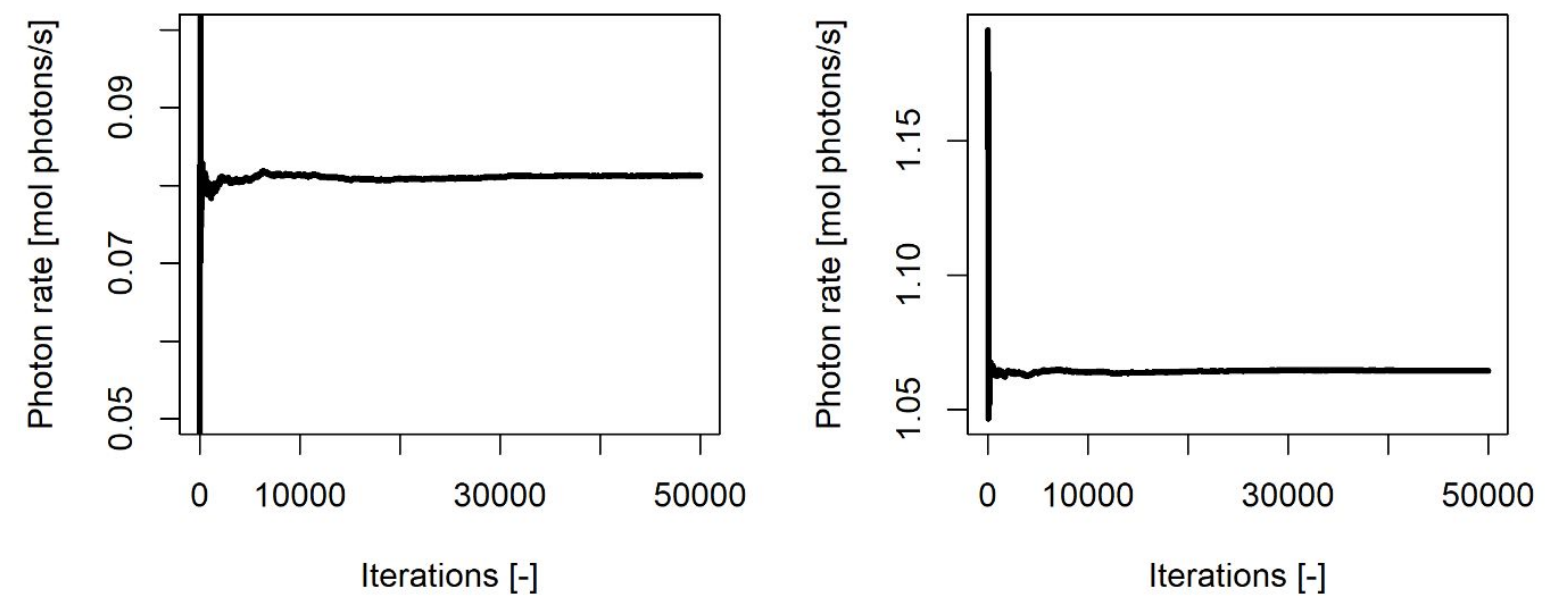

Figure 56 Convergence of standard deviation (left) and mean (right) scaled-up photon rate of Scenario 1.
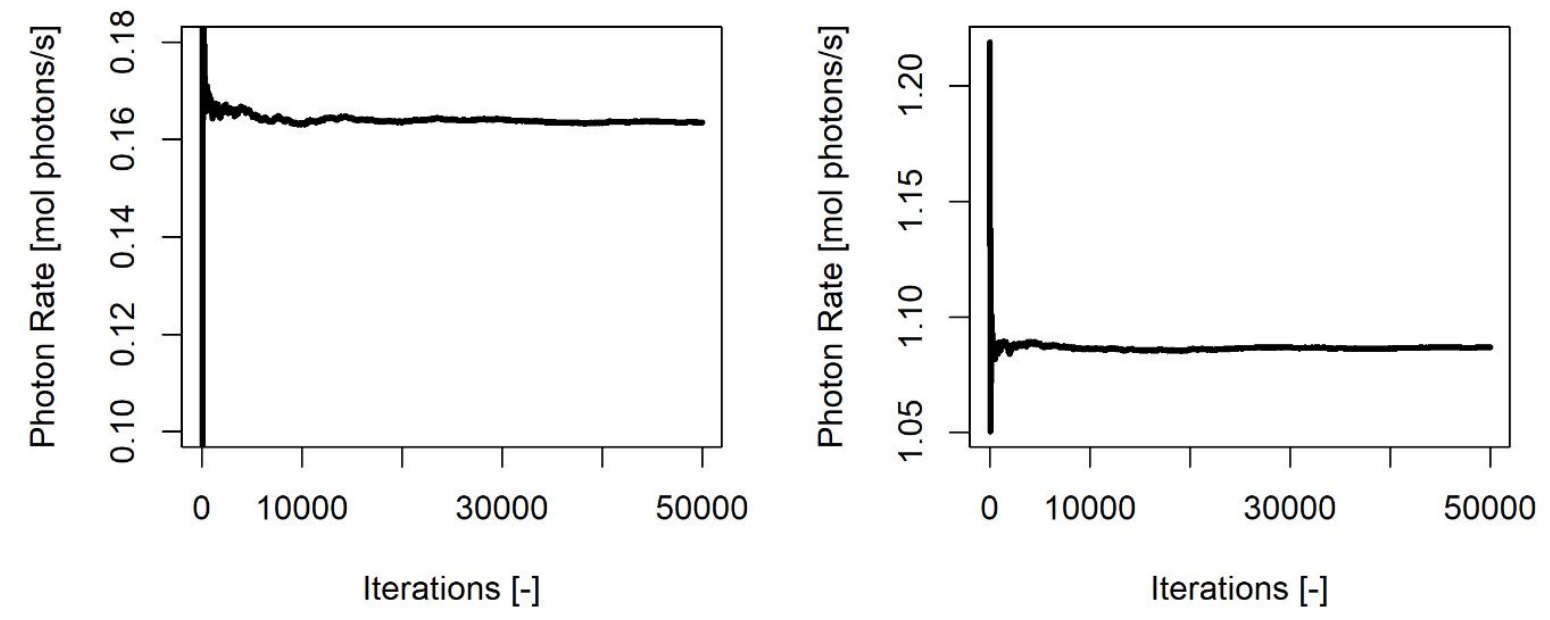

Figure S7 Convergence of standard deviation (left) and mean (right) scaled-up photon rate of Scenario 2. 

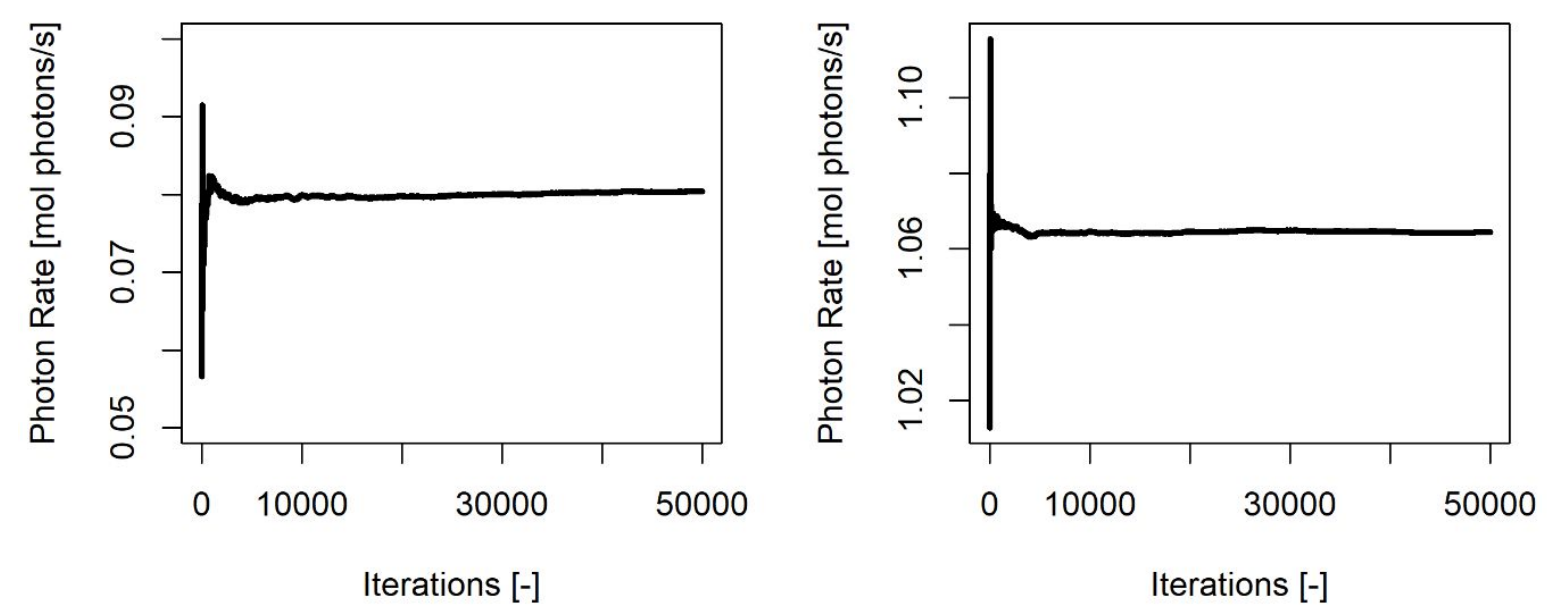

Figure S8 Convergence of standard deviation (left) and mean (right) scaled-up photon rate of Scenario 3.
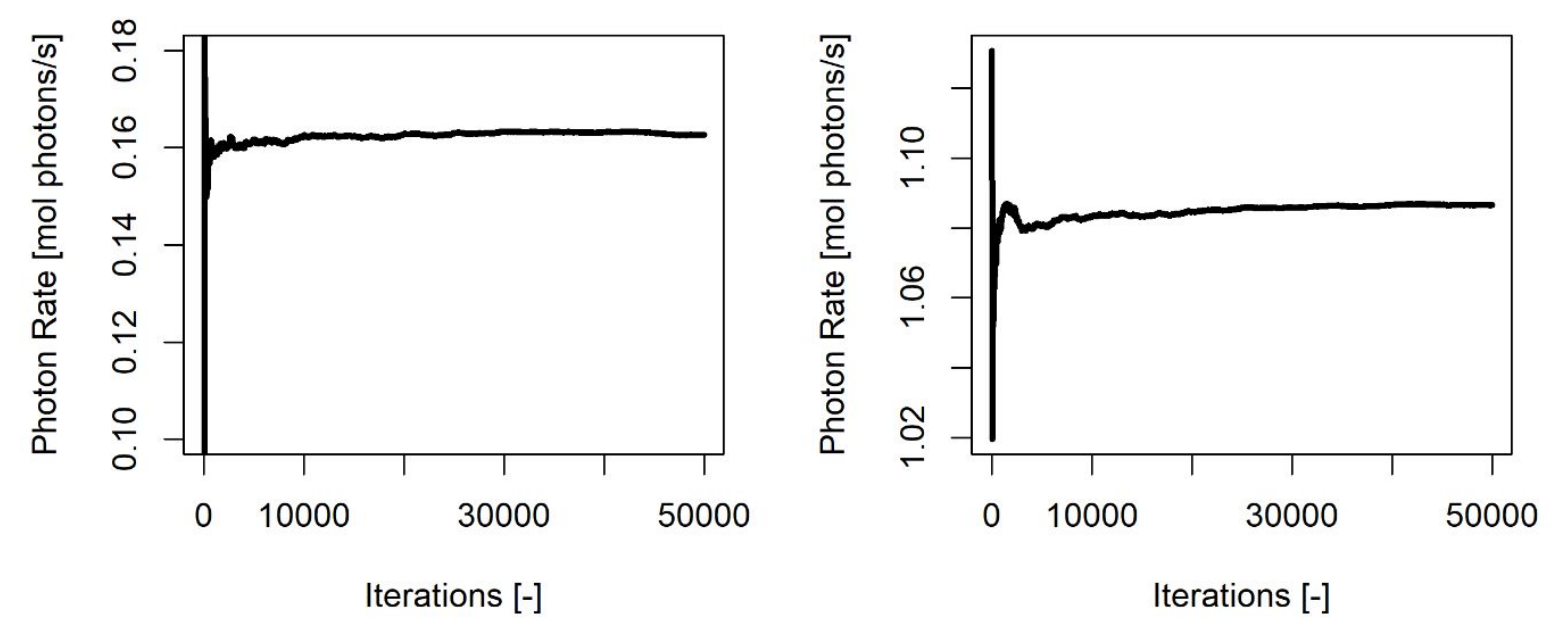

Figure 59 Convergence of standard deviation (left) and mean (right) scaled-up photon rate of Scenario 4.

\section{Reference}

1. Aillet, T.; Loubière, K.; Dechy-Cabaret, O.; Prat, L., Microreactors as a Tool for Acquiring Kinetic Data on Photochemical Reactions. Chemical Engineering \& Technology 2016, 39 (1), 115-122. 